\section{Jogos didáticos como recurso de fixação de conteúdos de química na Educação Superior}

\section{Didactic games as a resource for fixing chemistry content in Higher Education}

\author{
Ádria Thayssa Alves Pontes ${ }^{1}$, Camilla Costa de Sousa², Gabrieli Santos Oliveira ${ }^{3}$, Gustavo do \\ Rosário Costa ${ }^{4}$, Nádia Rosana Matos Soares ${ }^{5}$, Danay Rosa Dupeyrón Martell ${ }^{6}$
}

'Acadêmica de Farmácia. Instituto Macapaense de Ensino Superior-IMMES. Macapá-AP Brasil. E-mail: thayssaadria@gmail.com

${ }^{2}$ Acadêmica de Farmácia. Instituto Macapaense de Ensino Superior-IMMES. Macapá-AP Brasil. E-mail: costas.camilla@gmail.com

${ }^{3}$ Acadêmica de Farmácia. Instituto Macapaense de Ensino Superior-IMMES. Macapá-AP Brasil. E-mail: gabisaoli354@gmail.com

${ }^{4}$ Acadêmico de Farmácia. Instituto Macapaense de Ensino Superior-IMMES. Macapá-AP Brasil. E-mail: costagustavo1515@gmail.com

${ }^{5}$ Farmacêutica, Mestre em Ciências Ambientais, Coordenadora do curso de Farmácia do Instituto Macapaense de Ensino Superior -IMMES. Brasil. E-mail: soaresnadia@ig.com.br

${ }^{6}$ Química, Doutora em Biodiversidade Tropical, Professora do Instituto Macapaense de Ensino Superior. Macapá-AP Brasil. Email:danaydm@gmail.com *Autor para correspondência

\author{
Palavras-chave \\ Uno-químico \\ Jogo da memória \\ Jogo da velha \\ Dominó \\ Quebra-cabeça
}

\begin{abstract}
Em vários cursos da educação superior, em particular nos cursos de farmácia, a matéria de química tem se mostrado como um obstáculo para o estudante devido à dificuldade no aprendizado sobre os conceitos desta ciência, muitas vezes deficientes desde o ensino médio. Assim, o objetivo deste trabalho é apresentar cinco jogos didáticos voltados à química, desenvolvidos pelos graduandos do segundo período do curso de farmácia do Instituto Macapaense de Melhor Ensino Superior (IMMES). Os jogos são baseados em jogos tradicionais, no entanto construídos com informações de química selecionadas. Observou-se que a estratégia dos jogos trouxe a quebra dos padrões clássicos ensinados em sala de aula, vislumbrando uma didática mais atrativa. Deste modo, os acadêmicos demonstraram um especial interesse em participar da disciplina. Pode-se constatar também que o processo de ensino mediado pelos jogos proporcionou melhores condições para o entendimento da matéria. Estas ferramentas didáticas, onde o aprendizado acontece não apenas por assimilação de conceitos químicos repetitivos, permitem desmitificar a complexidade desta ciência, evitando que a matéria se torne cansativa e de difícil entendimento. Nesse sentido, os cinco jogos apresentados (uno químico, jogo da memória, jogo da velha, dominó e quebra-cabeça) poderão ser usados como recurso para fixação de conteúdos de química de uma maneira moderna e dinâmica. Assim, o emprego de métodos ativos de ensino-aprendizagem, em conjunto com as aulas expositivas, permite facilitar o contato dos alunos com a química, tornando o assunto compreensível e agradável.
\end{abstract} for the student due to the difficulty in learning about the concepts of this science, often deficient since high school. Thus, the aim of this work is to present five chemistry-oriented educational games developed by undergraduate students of the second period of the pharmacy course at the Instituto Macapaense de Melhor Ensino Superior (IMMES). The games are based on traditional games, but built with selected chemistry information. It was observed that the strategy of the games brought the break of the classic standards taught in the classroom, evidencing a more attractive didactics. In this way, scholars have shown a special interest in participating in the discipline. It can also be noted that the teaching process mediated by games provided better conditions for understanding the subject. These didactic tools, where learning happens not only through the assimilation of repetitive chemical concepts, allow demystifying the complexity of this science, avoiding that the subject becomes boring and difficult to understand. In this sense, the five games presented (Chemistry playing cards, memory game, tic-tac-toe, domino and puzzle) can be used as a resource for fixing chemistry contents in a modern and dynamic way. Thus, the use of active teaching-learning methods, together with lectures, facilitates students' contact with chemistry, making the subject understandable and enjoyable.

\section{Keywords}

Chemistry playing cards

Tic-tac-toe

Dominoes

Puzzle \section{.}


predominante não é uma das melhores para o ensino de química. Boa parte dos professores não procura alternar as aulas tradicionais com outras metodologias mais atraentes e eficientes que tornem a transmissão do conteúdo de química mais agradável (SILVA, 2019; SILVA; ARRUDA, 2019; SANTOS, 2014).

\section{Dificuldade de aprendizagem no nível superior}

De forma geral, nas escolas brasileiras, o ensino de química continua sendo tradicional, baseado na repetição de fórmulas, cálculos e na memorização do conteúdo. Este tipo de metodologia pedagógicas, baseado unicamente em aulas expositivas, é limitado e rígido, resultando em um prejuízo da eficiência didática e em um desestimulo do aprendizado dos estudantes. O emprego de metodologias pouco didáticas e uma visão excessivamente formal da disciplina na Educação Básica resultam na desvalorização desta ciência e no desinteresse observado nos acadêmicos no nível superior (AVANCINI, 2016). Assim, os alunos chegam ao ensino superior com dificuldades na química básica que foram se acumulando durante o processo de ensino-aprendizado nas escolas.

Outra realidade das escolas públicas brasileiras se dá pela falta de professores em sala ou até pela deficiência de planejamento na hora de distribuir a carga horária da matéria.

Diante deste cenário, um fato extremamente comum entre estudantes de cursos de graduação em Farmácia, Biomedicina, Enfermagem, Fisioterapia, Odontologia, Medicina entre outros, é a dificuldade em aprender química. Expressões como "não gosto de química" ou "é uma matéria muito difícil" são frequentes entre graduandos destes cursos. Incertezas sobre a importância e a necessidade desta disciplina, como parte do currículo acadêmico, são evidentes (VIEIRA, 1996 apud SANTANA).

\section{Relação dos jogos com o desenvolvimento humano}

O desenvolvimento humano se dá através da identidade e da autonomia dessa pessoa, promovendo o aprimoramento do processo cognitivo, motor e afetivo. Ao inserir os jogos nesse fator de crescimento, tem-se a intenção de incentivar a competitividade e o pensamento crítico de maneira saudável, o comportamento cooperativo, a autoconfiança, além de induzir ao questionamento e a construção de críticas próprias. O jogo é um instrumento construto da zona de desenvolvimento proximal, sendo capaz de conduzir o indivíduo a um nível de desenvolvimento superior ao que tem no presente - bem como oportuniza que sejam trabalhadas necessidades que no momento não podem ser realizadas, por meio do simbolismo (VYGOTSKY, 1988).

\section{Abordagem contemporânea do emprego de jogos didáticos}

A abordagem atual se dá através da busca pela interação do aluno com a matéria, iniciando a interação do aluno com os jogos didáticos, que visam o objetivo de repassar o conhecimento do assunto de maneira lúdica através dos mais diversos jogos desenvolvidos. A ideia dos jogos e facilitar a aprendizagem das pessoas de uma forma mais inovadora e atraente (NUNES; ADORNO, 2010; MATIAS, 2017; GOMES, 2018; OLIVEIRA, 2018; MAIA 2019). O jogo didático, assim como outros recursos, possui a capacidade de estimular a curiosidade, a iniciativa de participação e a autoconfiança do aluno; como também aprimora o desenvolvimento de habilidades linguísticas, mentais e de concentração, e exercitam interações sociais e trabalho em equipe (VYGOTSKY, 1989 apud ROCHA et al.). Por isso, os jogos lúdicos devem ser trabalhados como auxiliares na construção do conhecimento em qualquer área educacional. Na matemática é muito comum a sua utilização, principalmente nos primeiros anos de escolaridade. A biologia também faz uso desse recurso com certa frequência (CAMPOS, 2003). Na física e na química, os jogos têm sido um pouco menos utilizados, mas seu uso está aumentado bastante nos últimos anos (CUNHA, 2012; SALES, 2018). A maioria dos trabalhos encontrados na literatura atual está voltada para a educação básica, e de certa forma acaba causando um déficit no desenvolvimento desse trabalho para o nível superior.

As reflexões descritas neste trabalho resultam em uma análise crítico reflexiva sobre a aplicação de jogos didáticos de química no ensino superior. A ação contempla algumas atividades desenvolvidas em conjunto por acadêmicos e professores, em função de diminuir a visão de dificuldade de aprendizagem das matérias de química, em particular na formação farmacêutica. (VYGOTSKY, 1987).

Nesse contexto, verifica-se a necessidade de falar em educação química, priorizando o processo ensino/aprendizagem de forma contextualizada e estimulando o raciocínio para que os estudantes universitários possam perceber a importância socioeconômica desta área da ciência (VYGOTSKY, 1987). Assim sendo, o presente estudo teve como objetivo apresentar uma proposta metodológica envolvendo diferentes jogos que auxiliem na fixação de conteúdos das disciplinas de Química Geral e Físico-Química, abordados na educação superior. 


\section{MATERIAL E MÉTODOS}

O trabalho foi realizado por graduandos, do segundo semestre, do curso de farmácia da Faculdade Instituto Macapaense de Melhor Ensino Superior (IMMES), baseado em artigos, projetos de estudo em curso, artigos de revisão, teses e dissertações, tendo como objetivo apresentar uma proposta metodológica para fixação dos conteúdos de química na formação farmacêutica.

Primeiramente, foram ministradas aulas expositivas das disciplinas de Química Geral e Físico-Química, envolvendo vários tópicos como: Generalidades das disciplinas, boas práticas laboratoriais, distribuição eletrônica, estrutura atômica, tabela periódica, transformações da matéria, soluções, termodinâmica, entre outros.

Em uma segunda etapa, ocorreu a orientação do desenvolvimento de um jogo didático sobre os assuntos trabalhados em sala de aula. Assim, os acadêmicos ficaram responsáveis por desenvolver um jogo e as regras necessárias, podendo as mesmas ser iguais ou diferentes dos jogos tradicionais.

Os acadêmicos envolvidos no estudo construíram de forma individual os cinco jogos apresentados na Tabela 1, baseados em informações selecionadas e consideradas de maior relevância dos componentes curriculares. Durante a fase de confecção dos jogos os graduandos contaram como o auxilio e monitoramento do professor responsável pelas disciplinas.

Os jogos foram desenvolvidos fazendo uso de programas de computação tais como: Power Point, Word e Paint. Depois de concluídos, os jogos foram impressos e plastificados para garantir maior durabilidade. Maiores detalhes sobre as regras de cada jogo podem ser encontradas nos anexos A-D.

Por fim, após a turma ter reconhecido o conteúdo durante as aulas expositivas, os cinco jogos foram apresentados e testados em sala de aula, para a mesma turma dos autores do trabalho.

\section{RESULTADOS E DISCUSSÃO}

A execução dos jogos em sala de aula trouxe a possibilidade dos alunos exercitarem o cérebro e ao mesmo tempo criou a percepção de que há outras formas de aprender química. Foi possível observar que os acadêmicos ampliaram as relações e começaram a interagir com maior facilidade. A interação professor-aluno também ocorreu de forma espontânea, incentivando a participação e despertando o interesse de todos os alunos na atividade.

Durante a apresentação e discussão dos jogos o professor mediou e conduziu a atividade, baseado no interesse pelo conhecimento e lúdico que independe da faixa etária. Do total de 19 alunos com faixa etária entre 18 e 49 anos que jogaram (sendo $60 \%$ do sexo feminino e $40 \%$ do sexo masculino), $89 \%$ afirmaram ter gostado de participar do jogo, pela forma divertida de rever os conceitos de distribuição eletrônica, estrutura atômica, estados físicos da matéria, enquanto 10 \% parecem não ter gostado muito de participar do jogo, devido a que os mesmos não tinham conhecimento suficiente para se envolver no jogo.

No primeiro jogo, "Uno- químico", os alunos precisam usar conhecimentos básicos de química. O jogo é constituído por 75 cartas de cores variadas, sendo 60 cartas nas cores vermelha, azul, verde e amarela e 15 cartas de ação na cor preta. Nas cartas coloridas aparecem os símbolos de diferentes elementos químicos da tabela periódica assim como outras informações (nome, massa atômica, número atômico, eletronegatividade e estado de agregação). A partir das regras, os alunos passam a observar as cartas e fazem a jogada de acordo com as cores e os elementos que compõe o jogo. Notou-se que houve competição entre os discentes,

Tabela 1. Relação dos jogos desenvolvidos associados a diferentes assuntos abordados nas aulas de química.

\begin{tabular}{|c|c|c|}
\hline JOGOS & ASSUNTOS ABORDADOS & ÁREA DO JOGO \\
\hline 1. Uno Químico & Tabela Periódica & Química Geral \\
\hline 2. Jogo da Memória & Materiais utilizados em laboratório de Química & Química Geral \\
\hline 3. Jogo da Velha & $\begin{array}{l}\text { Conceitos básicos da Química e Físico-Química } \\
\text { Distribuição Eletrônica } \\
\text { Líquidos e Soluções } \\
\text { Termodinâmica } \\
\text { Tabela Periódica }\end{array}$ & $\begin{array}{l}\text { Química Geral } \\
\text { Físico-Química }\end{array}$ \\
\hline 4. Dominó & Tabela Periódica & Química Geral \\
\hline 5. Quebra-Cabeça & Tabela Periódica & Química Geral \\
\hline
\end{tabular}

Fonte: Autoria Própria (2019) 
saudável para o ensino, pois para cada elemento há uma surpresa nas cartas de ação (cartas pretas): bloqueio, curinga, inversão, $+2,+4$, conhecidas como cartas de punição. Este jogo de cartas pode ser considerado educativo já que possui o intuito de atingir conteúdos específicos tais como a memorização dos símbolos químicos e outras propriedades dos elementos.

No dia a dia dos acadêmicos de farmácia, percebe-se a dificuldade que o graduando tem em saber os principais equipamentos usados no laboratório de química, acarretando em acidentes e no uso incorreto desses materiais. Devido a isso, o segundo jogo "Jogo da memória laboratorial" abordou as vidrarias de laboratório como tema de aprendizado. As cartas com imagens coloridas contendo a função e o nome de cada vidraria facilita o aprendizado e promove a construção do conhecimento cognitivo e social. É importante mencionar que através do jogo é ratificado que cada vidraria possui uma função e modo de utilização específica, geralmente, diferente. Destaca-se que a aplicação deste tipo de jogo instrui a memória dos acadêmicos, pois para jogá-lo é necessário um raciocínio rápido e uma boa memória fotográfica. Com isso, a memória passa a ser estimulada e trabalhada. Com relação à aplicação deste jogo em sala podemos apontar que os estudantes ficaram mais interessados em conhecer cada uma das funções das vidrarias e equipamentos comumente empregados em sala de aula. Inclusive, um aluno da turma sugeriu realizar outro jogo de cartas da memória com itens de segurança no laboratório químico. Esta iniciativa pode ser considerada uma evidencia do interesse despertado nos acadêmicos.

No terceiro jogo, "Jogo da velha" químico, diferente do jogo tradicional, a proposta foi desenvolver cartas com conteúdos básicos da química para poder colocar a ficha no tabuleiro. Dentre os temas abordados estavam, por exemplo, estados físicos da matéria, distribuição eletrônica e tabela periódica. Para vencer o jogo é fundamental utilizar o $\mathrm{X}$ ou $\mathrm{O}$, de maneira vertical, diagonal e horizontal, e para efetivar uma jogada é necessário responder as perguntas de maneira correta. Esse jogo ajuda no desenvolvimento da estratégia, pois é preciso analisar a jogada do oponente para poder vencê-lo. Durante o desenvolvimento deste jogo foi fundamental a interação e comunicação aluno-professor. Apesar disso, foi possível notar certas dificuldades dos acadêmicos em confeccionar o gabarito de respostas, para o qual tiveram que estudar os conceitos teóricos abordados nas aulas expositivas, estimulando por tanto, a busca e construção do conhecimento individual e coletivo. Assim, do ponto de vista pedagógico, o jogo diversificou a revisão dos conteúdos já vistos pelos estudantes em sala de aula. Cabe mencionar que em um primeiro momento, os acadêmicos não acertavam as respostas ou não queriam responder por medo a errar na frente dos outros colegas. No entanto, na medida em que o jogo começou a fluir o número de participantes aumentou e as respostas acertadas foram de $75 \%$.

Através do quarto jogo, "Jogo de dominó da tabela periódica", os estudantes tinham a possibilidade de revisar alguns conceitos fundamentais como a nomenclatura dos elementos químicos assim como o número atômico de cada um deles. Ao mesmo tempo foram definidas diferentes cores para facilitar a associação dos elementos com os grupos em que os mesmos aparecem representados na tabela periódica. Durante a execução do jogo, um estudante sugeriu aumentar o grau de dificuldade do jogo colocando em algumas cartas o elemento químico e em outras os respectivos nomes dos elementos para que o estudante tivesse que conhecer os nomes e símbolos dos elementos químicos para poder colocar a ficha. Este comentário demonstra interesse e envolvimento dos estudantes no jogo. A dificuldade no tocante aos nomes e símbolos servirá como estimulo para o uso da tabela periódica, proporcionando-Ihes mais familiaridade em saber manuseá-la (FERREIRA et al., 2019).

Apesar da simplicidade do quinto jogo, o "Quebra- cabeça da tabela periódica" é um jogo onde a pessoa deve resolver um problema proposto sendo necessário ter agilidade para jogá-lo. O jogo é interessante e envolve todos os elementos da tabela periódica. Durante a montagem do mesmo, os acadêmicos vão visualizando a ordem dos elementos na tabela periódica, permitindo que o estudante revise estes conteúdos de forma didática. Além disso, o jogo estimula o cérebro e ajuda a desenvolver o raciocínio lógico dos participantes, através da percepção visual e a necessidade de concentração. Durante a execução do jogo em sala de aula, o professor comentou que seria interessante criar um quebra cabeça onde cada elemento fosse uma ficha do jogo. Dessa forma a montagem do quebra-cabeças ajudaria a memorizar a posição de cada elemento na tabela periódica.

A proposta metodológica empregando jogos para a fixação dos conteúdos trouxe a quebra dos padrões clássicos ensinados em sala de aula, vislumbrando uma didática mais atrativa. Pode-se constatar que o processo de ensino mediado pelos jogos proporcionou melhores condições para o entendimento da matéria. Os estudantes manifestaram verbalmente que os conteúdos já não pareciam tão complexos e de difícil entendimento, fazendo um diferencial no aprendizado, que aconteceu não apenas por assimilação de conceitos químicos repetitivos. A partir disso, nota-se que o papel do professor é essencial na busca de metodologias que criem situações favoráveis para aumentar a eficácia da aula expositiva.

Almeida (1978), afirma que os jogos não devem ser fins, mas meios para atingir objetivos. Estes devem ser aplicados para o benefício educativo. Trata-se de uma forma didática 
Figura 1. Imagens ilustrativas dos jogos desenvolvidos pelos acadêmicos. Nota. (A): Uno Químico, (B): Jogo Da Memória, (C): Jogo da Velha, (D): Dominó, (E): Quebra-Cabeça.

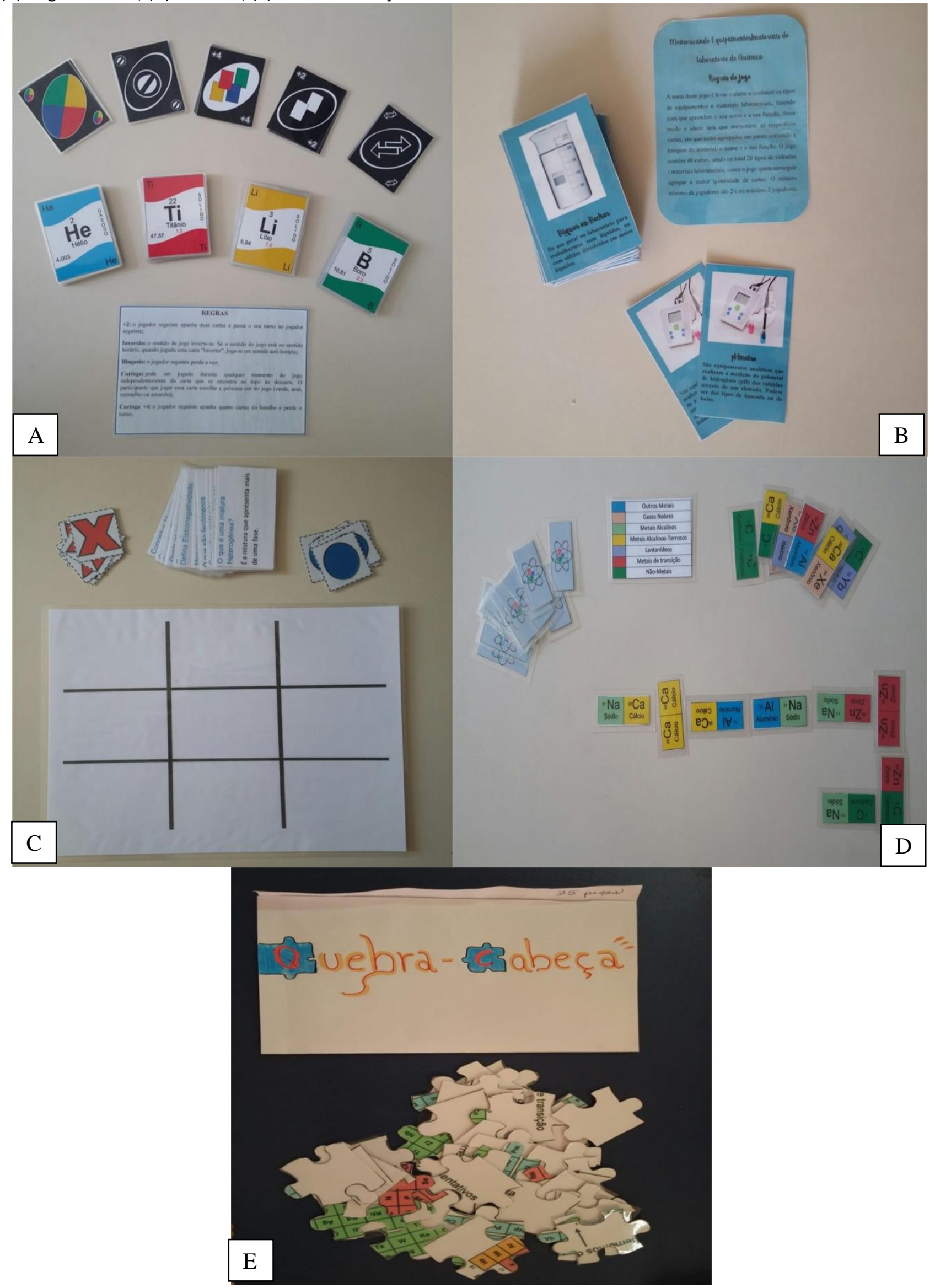

Fonte: Autoria Própria (2019). 
para melhorar o aprendizado nas salas de aula. Cabe ressaltar que os jogos são ótimos instrumentos de socialização. Assim, os alunos passam a se interessar pelas diferentes matérias, adotando os jogos como nova forma de estudar em grupo.

Segundo Miranda (2001), mediante o jogo didático, vários objetivos podem ser atingidos, relacionados à cognição (desenvolvimento da inteligência e da personalidade, fundamentais para a construção de conhecimentos); afeição (desenvolvimento da sensibilidade e da estima e atuação no sentido de estreitar laços de amizade e afetividade); socialização (simulação de vida em grupo); motivação (envolvimento da ação, do desfio e mobilização da curiosidade) e criatividade.

Ao desenvolver em sala de aula um trabalho com jogos, o professor, está não só desenvolvendo os aspectos cognitivos dos alunos, mas passando também a enfatizar os aspectos afetivos que são resgatados durante o momento lúdico. Como consequência do antes mencionado, a experiência de estes métodos passou a melhorar a visão dos alunos com relação à química, desmitificando assim a hipercomplexidade desta matéria.

A aplicação de instrumentos de coletas de dados que permita realizar uma avaliação quantitativa e verificar a melhora na aprendizagem dos conteúdos abordados através destes jogos será realizada em um futuro próximo. Essa etapa será conduzida por estudantes do próprio curso de farmácia onde foram desenvolvidos os jogos.

Por último, é oportuno lembrar que, no nível superior, junto com o emprego de novas estratégias didáticas, a aula expositiva dialogada com a participação ativa dos estudantes ainda é essencial para discorrer, transmitir e sintetizar informações sobre um tema de forma organizada e sistemática. Diante deste pressuposto e concordando com Madeira (2015), o emprego de jogos deve ser considerado uma ferramenta complementaria para a fixação de conteúdos previamente abordados pelo professor.

\section{CONSIDERAÇÕES FINAIS}

Neste trabalho foi apresentada uma proposta metodológica, envolvendo cinco jogos didáticos adaptados para conteúdos de Química Geral e Físico-Química, a fim de buscar aproximação entre os graduandos e facilitar a fixação dos assuntos abordados nestes componentes curriculares.

Verificou-se que, através dos jogos aqui apresentados, quebra-se o distanciamento aluno-aluno e aluno-professor, pois tanto os professores como o conjunto de alunos fazem parte das ações que levam à melhor compreensão dos conceitos estudados.

Durante a apresentação dos jogos, a sala de aula tornou- se um espaço de confiança, de aceitação e de afetividade, transmitindo segurança no processo de aprendizagem. De forma qualitativa, verificou-se que o uso dos jogos proporciona interação e auxilia o processo de construção dos conhecimentos adquiridos, proporcionando prazer pelo aprender.

Mesmo que nesta primeira etapa, ainda não tenha sido empregado um instrumento para coleta de dados quantificáveis, pode se observar que todos os jogos foram atraentes, causando diversão e entrosamento entre os acadêmicos, resultando em melhores estratégias para dar respostas aos questionamentos. Além disso, os cinco jogos representam uma forma educacional adequada e de boa qualidade para atingir a fixação de conteúdos do plano de ensino curricular.

Assim, o ato de estudar e/ou ensinar química brincando tornou-se mais eficiente e produtivo do que com os métodos tradicionais, demonstrando que a brincadeira pode trazer benefícios para as pessoas não somente no período da infância, mas em todos os momentos de nossas vidas.

\section{AGRADECIMENTOS}

Os autores agradecem ao acadêmico Alisson Moraes, do curso de Farmácia do IMMES, pelo apoio na formatação do jogo de dominó da tabela periódica.

\section{REFERÊNCIAS}

AVANCINI, M. Aprender química para quê?. Disponível em <http://www.revistaeducacao.com.br/quimica-pra-que>. Acesso em 14 de outubro de 2019.

CAMPOS, L. M. L.; BORTOLOTO, T. M.; FELICIO, A. K. C. A produção de jogos didáticos para o ensino de ciências $\mathrm{e}$ biologia: uma proposta para favorecer a aprendizagem. Cadernos dos Núcleos de Ensino, São Paulo, p. 35-48, 2003. Disponível em; <http:// www.unesp.br/prograd/PDFNE2002/aproducaodejogos.p df>.Acesso em: 20 de outubro 2019.

CUNHA, M. B. da. Jogos no Ensino de Química: Considerações Teóricas para sua Utilização em Sala de Aula. Química Nova na Escola, v.34, n.2, p. 92-98, maio. 2012.

DUPEYRON, D. R.; SOARES, N. R. M; VEIGA, R. R; NASCIMENTO, I. da S.; da SILVA, J. P; OLIVEIRA, I. dos S; ALBERTO, A. K. M; dos SANTOS, N. T. R.; dos SANTOS, B. L; SILVA, C. G; de OLIVEIRA, A. L; ALBERTO, A. G. M; BOTASCRUZ, G. da S. Desafios e perspectivas no ensino de química: uma reflexão a partir da experiência no curso de farmácia do IMMES. Revista Arquivos Científicos (IMMES) 49-58, v.2 n. 2019. 
FERREIRA, E. A.; GODOI, T. R. A.; SILVA, T. P. da; ALBUQUERQUE, A. V. de; Aplicação de Jogos Lúdicos para o Ensino de Química: Auxilio nas Aulas sobre Tabela Periódica. Disponível em <https://docplaer.com.br/1353410-Aplicacao-de-jogosludicos-para-o-ensino-de-quimica-auxilio-nas-salassobre-tabela-periodica.html >. Acesso em 01 de outubro de 2019.

GOMES M., N.; da SILVA P., M.G.; RIBEIRO DA S., J.; GUIMARÃES B., ELIEL. Memorizando vidrarias: uma atividade para ensino de química. Revista Tecné, Episteme y Didaxis. Número Extraordinário. ISSN impreso: 01213814, ISSN web: 2323-0126. 2018.

MADEIRA M. C. Situações em que a aula expositiva ganha eficácia. V Seminário Internacional sobre Profissionalização Docente (SIPD/CÁTEDRA UNESCO). ISSN 2176-1396. Curitiba. 2015.

MAIA, A. L. S. dos; COSTA, K. P. da. Jogo Didático: Instrumento para Facilitar o Entendimento da Química Orgânica Possibilitando Discussão e Aprendizado em Sala de Aula. Disponível em <http://www.editorarealize.com.br/revistas/conedu/trab alhos/TRABALHO_ev117_mda_SA16_ID3760_080920181 25218.pdf >. Acesso em 01 de outubro de 2019.

MATIAS, F. S. da; NASCIMENTO, F. T. do; SALES, L. L. M. de. Jogos Lúdicos como Ferramenta no Ensino de Química: Teoria versus Prática 1. Revista de Pesquisa Interdisciplinar, n.2, p. 452-44, 2017.

MIRANDA, S. No Fascínio do jogo, a alegria de aprender. In: Ciência Hoje, v.28, 2001 p. 64-66.

OLIVEIRA, A. L. de; OLIVEIRA, J. C. P. de; NASSER, M. J. S. ; CALVACENTE, M. P. da. O Jogo Educativo como Recurso Interdisciplinar no Ensino de Química. Química nova na escola. São Paulo-SP, BR Vol. 40, N² 2, p. 89-96, 2018.

ROCHA, M. F. de; LIMA, I. C.de; VICTOR, C. M. B.; SANTANA, L. S. de; SILVA, L. P. da; Jogos didáticos no ensino de química. Disponível <http://quimimoreira.net/jogos\%didaticos\%202.pdf >. Acesso em 02 de outubro de 2019.

SANTANA, P. C. de; A importância do ensino da química e seu conhecimento na formação universitária de profissionais de saúde. Disponível em: $<$ https://meuartigo.brasilescola.uol.com.br/quimica/aimportancia-ensino-quimica-seu-conhecimento-naformacao-universitaria-de-profissionais-saude.html>. Acesso em 6 de outubro de 2019.

SANTOS, L. M; SILVA, P. R. A; MEDEIROS, R. B; FERREIRA, J. M. Congresso Internacional de Professores PDVL: Avaliação das dificuldades na aprendizagem de química. 2014.

SALES, M. F.de; SOUZA, G. A. P.; SILVA, A. A.; SILVA, K. L. da. Um jogo didático para o ensino de química: uma proposta alternativa para o conteúdo de equílibrio químico. South American jornal of basic Education, Tecnnical and Technological. ISSN: 2446-4821, V5. N2. P.125-137. 2018. SILVA, A. M. da; ARRUDA, S. M. Proposta para Tornar o Ensino de Química mais Atraente. Disponível em <http://www.abq.org.br/rgi/2011/731/RQI-731-pagina7Proposta-para-Tornar-o-Ensino-de-Quimica-maisaraente.pdf >. Acesso em 02 de outubro de 2019.

SILVA, L. R. B. da; BARBOZA, R. J. O. de; MATOS, J. G. J. de; LIRA, M. M. R. de. A importância do uso de jogos didáticos e suas contribuições para o ensino de química. Disponível em:

<http://www.editorarealize.com.br/revistas/conedu/trab alhos/TRABALHO_EV056_MD4_SA18_ID3179_16082016 195444.pdf >. Acesso em 20 de outubro de 2019.

TAVARES, A. J.; SAARA LÍDIA, C. L.; SAARA LIDIANA, C. L.; LIMA, M. A. A. Memorizando vidrarias: jogo didático para alunos de química. Instituto Federal de Educação, Ciência e Tecnologia do Rio Grande do Norte-IFRN. Disponível em: $<$ http://www.scielo.mec.pt/scielo.php?script=sci_arttext \&pid=S1645-72502012000300011 $>$.Acesso em: 20 de outubro de 2019.

VYGOTSKY, L. S. Pensamento e Linguagem. São Paulo: Martins Fontes, $1987 . \quad$ Disponível em: <http://www.scielo.mec.pt/scielo.php?script=sci_arttext \&pid=S1645-72502012000300011 $>$.Acesso em: 20 de outubro de 2019.

VYGOTISKY, L. S. Aprendizagem e desenvolvimento intelectual na idade escolar. 2. ed.São Paulo: ícone, P.103-117, 1988.

\section{ANEXOS}

\section{ANEXO A. UNO Químico}

Regras:

Ao início do jogo são distribuídas sete cartas a cada jogador, fora a parte a quantia que sobrar e deixado no canto e essas seriam as cartas de compra. Consiste em basicamente a ideia do jogo original, como que a função e você jogar todas as suas cartas até ficar sem nenhuma, o jogo e constituído por cartas no qual tem as cores (amarelo, azul, vermelho, verde e preto, sendo que as últimas seriam as cartas de ação).

No início do jogo os jogadores podem começar no sentido horário ou anti-horário. Assim, o jogador que começar posicionará uma carta com uma determinada cor, um número de eletronegatividade, e a nomenclatura do sólido ou líquido da tabela periódica.

Regras de posicionamento: na seguinte vez do jogador ou até mesmo a sua vez caso não tenha a mesma cor da carta ao topo do jogo, o mesmo poderá posicionar uma carta no qual 
tenha o número de eletronegatividade no qual seja parecido, ou que tenha a diferença de maior ou menor ou igual a 0,5 mesmo que seja de cor diferente.

Coringa: pode ser jogado durante qualquer momento da partida independentemente da carta que se encontrar no topo do descarte, o jogador que jogar essa carta escolhe a próxima cor ao jogo (verde, vermelho, amarelo, azul).

Coringa +4: o jogador seguinte apanha quatro cartas e perde a vez no mesmo turno;

Bloqueio: o jogador seguinte perder a vez;

Coringa +2 : o jogador seguinte apanha duas cartas e passa sua vez ao jogador seguinte

Inversão: o sentido do jogo inverte-se. Se o seguinte do jogo estiver em sentido horário, quando jogado uma carta "inverter", joga-se em sentido anti-horário;

No seguinte momento que um dos jogadores jogar sua última carta deverá gritar "Química" e assim e o fim do jogo.

Figura 2. Cartas ilustrativas do Uno Químico.

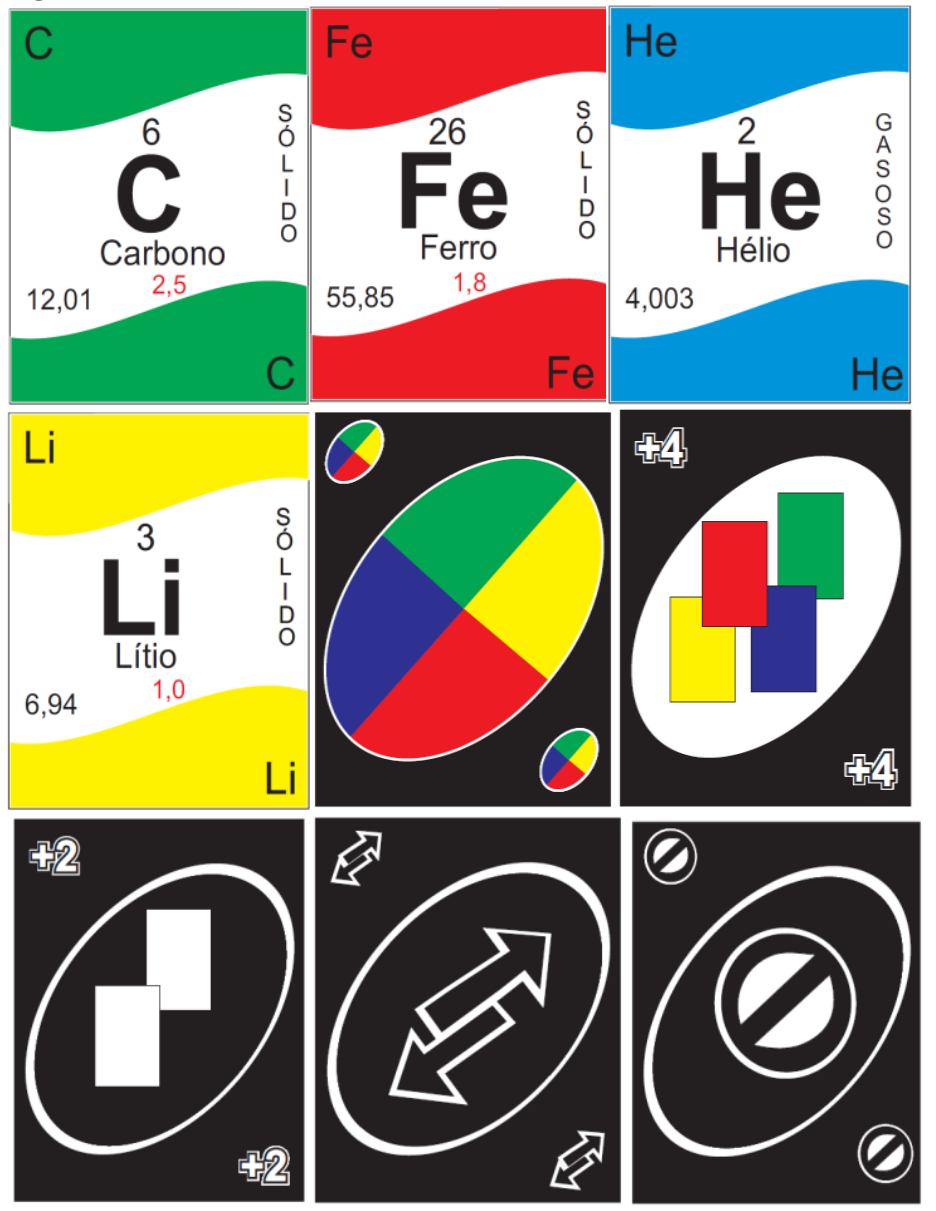

ANEXO B. Jogo da Memória Laboratorial

Regras:

A meta deste jogo é levar o aluno a conhecer os tipos de equipamentos e materiais laboratoriais, fazendo com que aprendam o seu nome e a sua função, desse modo o aluno tem que memorizar as respectivas cartas, que estão agrupadas em pares, contendo a imagem do material, o nome e a sua função. 0 jogo contém 40 cartas, sendo no total 20 tipos de vidrarias laboratoriais, vence o jogador que conseguir agrupar a maior quantidade de cartas. O número mínimo de jogadores é 2 pessoas e no máximo 3 jogadores.

Figura 3. Cartas ilustrativas do Jogo da Memória
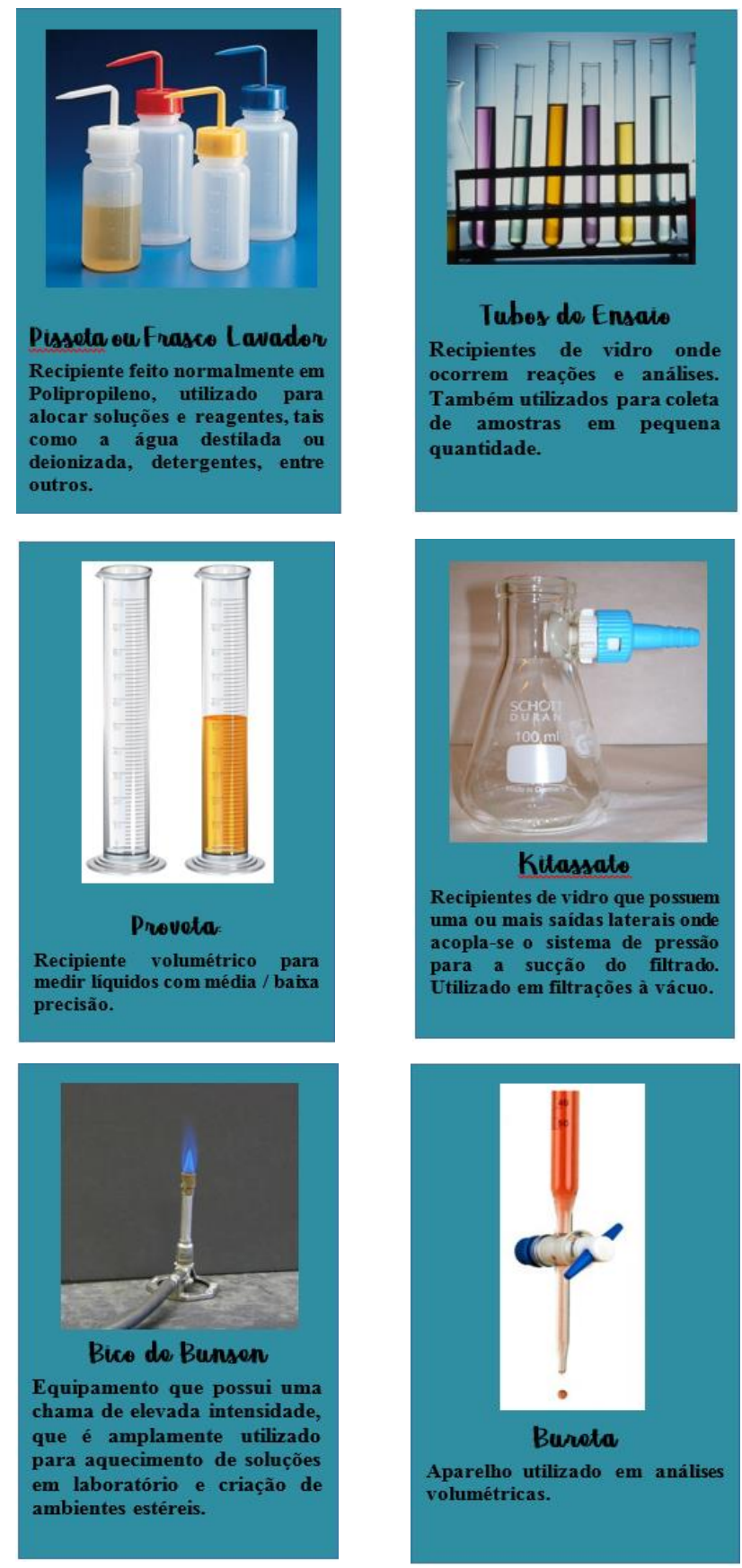

ANEXO C. Jogo da velha

Regras do jogo:

Participam dois jogadores (ou duas equipes), que jogam alternadamente, preenchendo cada um dos espaços vazios no tabuleiro, com (O) ou (X). 
O objetivo é conseguir três símbolos iguais ( $\mathrm{O}$ ou $\mathrm{X}$ ) em linha, quer horizontal, vertical ou diagonal, e ao mesmo tempo, quando possível, impedir o adversário de ganhar na próxima jogada.

O adversário é quem deve retirar a ficha com questões de química para o jogador que está na vez.

Se o jogador que está na vez acertar a pergunta, o jogador terá o direito de colocar a peça no tabuleiro.

Em cada rodada, o jogador tem direito de retirar apenas uma ficha, se não conseguir respondê-la deverá passar sua vez.

Figura 4. Tabuleiro e Cartões de perguntas ilustrativas do Jogo da velha.

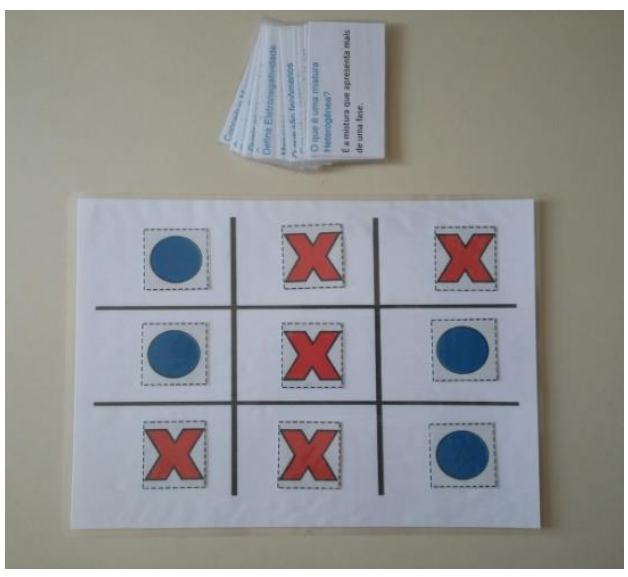

Qual o conceito de Química?

É a ciência que estuda a matéria, as suas transformações e a energia envolvida nesses processos.

Conceitue Matéria.

É tudo que ocupa um lugar no espaço (apresenta volume) e tem massa.

\section{O que é uma Mistura Homogênea?}

É a mistura que apresenta uma única fase.

\section{O que é uma mistura Heterogênea?}

É a mistura que apresenta mais de uma fase.

\section{O que são fenômenos Químicos?}

São aqueles em que ocorre mudança na composição química do material.

\section{Conceitue Energia.}

É a medida da capacidade de realizar um trabalho.

ANEXO D. Dominó de elementos da tabela periódica

Regras:

O jogo consta de 28 peças retangulares como no dominó tradicional. Podem participar até 4 pessoas, com um total de sete peças (ou pedras) para cada um. Joga-se da mesma forma que um dominó tradicional:

- Cada jogador recebe 7 pedras quando começa a rodada.

- O jogo se inicia com uma peça de qualquer elemento químico (pode ser sorteado)

- Se na partida houver menos de 4 jogadores, as pedras restantes ficam no dorme para serem compradas.

- A partir desse momento, os jogadores realizam suas jogadas, por turnos e no sentido anti-horário.

- Cada jogador, no seu turno, deve colocar uma das suas pedras em uma das 2 extremidades abertas, de forma que o elemento químico coincida. As dobradas são colocadas de maneira transversal para facilitar sua localização.

- Após o jogador colocar sua pedra sobre a mesa passa-se o turno ao seguinte jogador.

- Se um jogador não puder jogar, deverá "comprar" do dorme tantas pedras como forem necessárias. Se não houver pedras no dorme, passará o turno ao seguinte jogador.

- A partida continua com os jogadores colocando suas pedras sobre a mesa até que se apresente alguma das seguintes situações: Quando um jogador coloca sua última pedra na mesa, essa ação é chamada de bater ou caso nenhum dos 
jogadores possa continuar a partida (ocorre quando o elemento químico das extremidades já saiu 7 vezes). Nesse momento se diz que a partida está fechada.

- Ganha a partida quem primeiro terminar as peças ou quem tiver a soma menor dos números atômicos.

Figura 5. Fichas ilustrativas do Jogo de dominó da tabela periódica.
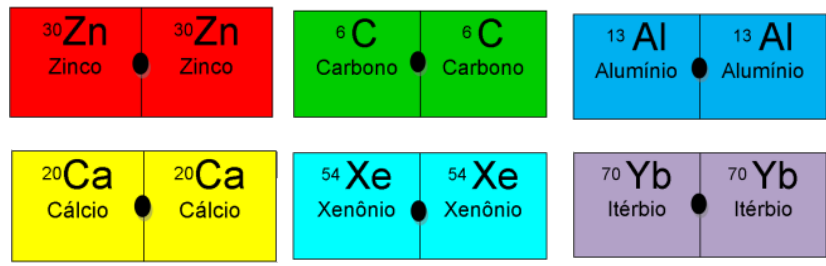

ANEXO E. Quebra cabeça da tabela periódica

Regras:

1- Para montar o quebra-cabeça, tendo como intuito aprender os elementos da tabela periódica, podem participar de 2 a 3 jogadores. 0 jogo também serve para reforçar a classificação geral dos elementos (representativos, de transição e de transição interna), diferenciando também os gases nobres.

Figura 6. Foto do quebra cabeça da tabela periódica.

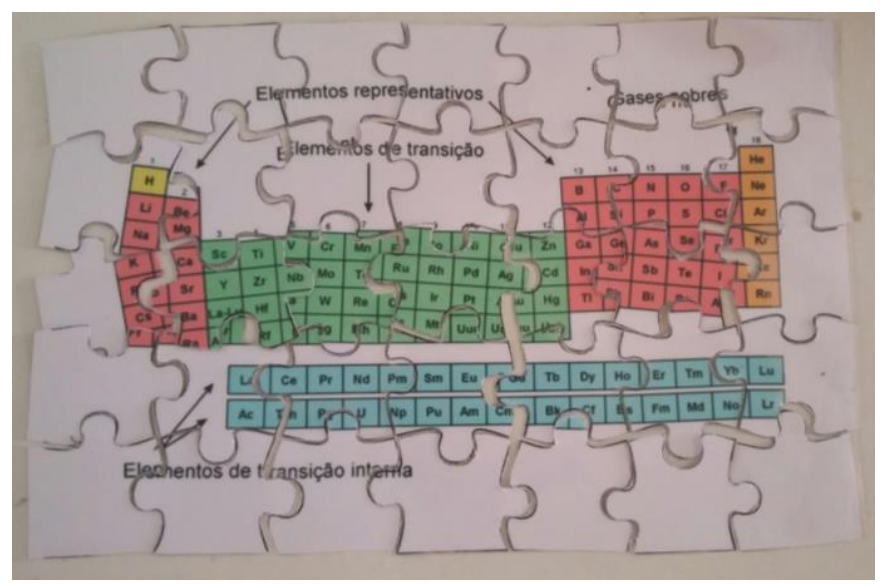

Submissão: 09/11/2019

Aprovado para publicação: 24/01/2020 